\title{
The infrequency of malignant disease in diaphyseal aclasis and neurofibromatosis
}

\author{
$S$ VOUTSINAS AND RUTH WYNNE-DAVIES
}

From the Department of Orthopaedic Surgery (Clinical Genetics), University of Edinburgh, Edinburgh EH8 $9 L N$.

SUMMARY The association of diaphyseal aclasis and neurofibromatosis with malignant neoplasms has been variously reported as between 5 and $28 \%$ of all cases, but malignant disease invariably presents at hospital and the true frequency from an unselected group is unknown. The current survey reviews not only hospital patients but also their affected relatives, with particular reference to malignant disease and the cause of death in all family members. A survey of 36 index patients and 80 known affected relatives with diaphyseal aclasis and 37 index patients and 33 known affected relatives with neurofibromatosis has been carried out. The observed proportions with associated malignant disease were $0.9 \%$ of all cases of diaphyseal aclasis and $4.3 \%$ of neurofibromatosis. The authors consider this is still too high an estimate in view of the number of persons in the families only mildly affected by the inherited disease who cannot be identified, although their malignant disease will be known. A more likely figure for malignant change in diaphyseal aclasis is calculated at $0.5 \%$ (or $1.3 \%$ of those over 21 years) and in neurofibromatosis $2.0 \%$ (or $4.2 \%$ of those over 21 years).

Diaphyseal aclasis and neurofibromatosis are both developmental disorders of autosomal dominant inheritance, the former affecting the skeleton and the latter principally the supportive tissues of the nervous system, although bony pathology also occurs.

Their association with malignant neoplasms is well known, the frequency being variously recorded as between 5 and $28 \%$ of all cases, ${ }^{1-7}$ but patients with malignant disease inevitably present at hospital and are frequently selected for reporting.

The current survey differs from previous reports in aiming to review not only hospital patients with diaphyseal aclasis and neurofibromatosis, but also their relatives, with particular reference to malignant disease and the cause of death in all family members, not only those known to be affected with the inherited disorder. Diaphyseal aclasis is one of the commoner skeletal dysplasias, with an estimated prevalence in the population of about 9 per 1000000 (WynneDavies and Gormley, unpublished data, 1981). It is characterised by multiple exostoses limited to enchondral bone, usually arising in the juxtaepiphyseal region of the long bones but also

Received for publication 25 January 1983. Accepted for publication 3 February 1983. frequently present in the pelvis, scapula, and ribs. The age of onset (or diagnosis) varies from birth to adult life, but over $80 \%$ are diagnosed during the first decade. ${ }^{8}$ Complications can arise from pressure on vessels, peripheral nerves, spinal cord, or viscera, although neurological complications are uncommon. ${ }^{9}$ Life expectancy is not shortened unless malignant degeneration occurs. Figures from the Scottish Bone Tumour Registry have recorded 125 cases of chondrosarcoma, eight of them being secondary to diaphyseal aclasis $(6.4 \%)$. Six of the eight presented between 18 and 33 and the other two at 42 and 52 years. This showed a younger age distribution than primary chondrosarcoma, where the peak incidence was between 41 and 70 years of age (M Catto, personal communication, 1981). The commonest site is in exostoses around the hip joint and is the exostotic or peripheral chondrosarcoma type, ${ }^{10}$ which remains localised for many years. ${ }^{11}$ Neurofibromatosis is one of the commoner inherited disorders, with a likely population incidence of 1 in 2000 to 3000 live births. ${ }^{12}{ }^{13}$ It principally affects the supportive tissues of the nervous system, both central and peripheral, but may involve all neuroectodermal and mesodermal tissues. ${ }^{14}$ Age of diagnosis is variable, ranging from birth to late 
adult life, with an equal sex ratio. The multisystemic features of the disorder are well known, café-au-lait patches, multiple neurofibromata, soft tissue and bone hypertrophy, scoliosis, and other spinal deformities being among the commoner signs. There appear to be two types of the disease: the central, with multiple schwanomas of cranial and spinal nerves frequently associated with other intracranial, dural, and intraspinal tumours and abnormalities, and the peripheral with the well known café-au-lait patches and multiple neurofibromata. Richardson and colleagues ${ }^{15}$ reported some overlap between them but noted that the peripheral type rarely exhibited central manifestation of the disease. Kanter et al $^{16}$ suggested the 'central' and 'peripheral' types were two distinct genetic diseases.

Malignant change may occur in neurofibromata or arise de novo in neurogenic tissue. Sarcomata usually arise in deep structures but occasionally superficially. ${ }^{1}$ No instance of malignant change has been reported in a subcutaneous nodule. ${ }^{17}$ D'Agostino et al ${ }^{18}$ reported 21 patients with sarcomata, the mean age being 28 years.

In addition to tumours of clearly neurofibromatous origin, a variety of other malignant neoplasms may occur, for example, glioma, astrocytoma, phaeochromocytoma, rhabdomysarcoma, liposarcoma, Wilms's tumour, and non-lymphocytic leukaemia. The presence of one of these disorders does not exclude the possibility of a neural crest origin, since a wide spectrum of metaplasias has been attributed to Schwann cells, or possibly the gene for neurofibromatosis merely increases the risk for a multiplicity of neoplasms. ${ }^{19}$

\section{Material and method}

There were 36 index patients with diaphyseal aclasis (14 male, 22 female) and 37 with neurofibromatosis ( 15 male, 22 female). All had been ascertained by a search of the hospital records at one of four hospitals (see acknowledgements), and all were subsequently examined there by one of the authors (RWD) and their pedigrees recorded.

Of the 47 first degree relatives affected with diaphyseal aclasis, 30 were examined personally, three had died, and one was abroad. Medical records were obtained for radiological confirmation of the diagnosis in all unavailable patients, as well as for the more distant second and third degree relatives. Of the 27 first degree relatives affected with neurofibromatosis 18 were examined personally, six had died, and one was abroad. Again, medical records were obtained for confirmation of the diagnosis in the remaining affected members of the family, the diagnostic criteria being a minimum of five café-aulait patches $1.5 \mathrm{~cm}$ in diameter.

Enquiry was made relating to malignant disease and the cause of death of all members of the family, since, even if the presence of these inherited disorders was unknown to the index patient, the presence of 'cancer' was likely to be. Medical evidence, including necropsy reports, was sought for all those with suspected malignancy. There were no index patients with malignant disease in the current survey, since neither the patients nor families of those noted in hospital records could be traced.

\section{Results}

DIAPHYSEAL ACLASIS

One-half of the index patients presented between the ages of 2 and 10 years, approximately one-quarter under the age of one year, and one-quarter over 11 years, only two being over the age of 21 when the disorder was first noted. The mean age of index patients at the time of the survey was 25.88 years, and of their affected relatives 61.40 years. The total number of persons in the family together with those affected by the same disorder are shown in table 1 noting also malignant bone or other neoplasms.

No case of chondrosarcoma was confirmed, and there was only one doubtful report of death from malignant change in an exostosis. (This male patient aged 66 years had had pain in his chest for 9 months when biopsy of a rib was carried out. No malignancy was reported, but he died shortly afterwards. There was no necropsy.) The distribution of non-bony neoplasms in first and second degree relatives dying from cancer was unremarkable.

Thus, of a total of 116 index patients and relatives with confirmed diaphyseal aclasis, there was only one with possible malignant change $(0.9 \%)$. If only those patients over the age of 21 years are considered, the proportion is 1 of $76(1.3 \%)$. Since there is only this one unconfirmed case of malignant degeneration, it cannot be deduced whether the degree of severity of diaphyseal aclasis is related to the frequency of malignant change.

NEUROFIBROMATOSIS

One-third of the index patients presented under the age of 2 years, one-third between 2 and 10 , and one-third between 11 and 20 years. The average age of index patients was $17 \cdot 10$, and of affected relatives 34.50 years. The total number of persons in the family together with those affected by the same disorder are shown in table 2 , noting all cases of malignant disease. There were two patients with malignant change in a neurofibroma and one confirmed and two unconfirmed with other malignant . 於 $\stackrel{\bar{\partial}}{0}$ 無 总 
TABLE 1 Possible malignant change in diaphyseal aclasis.

\begin{tabular}{|c|c|c|c|c|c|}
\hline & \multirow{2}{*}{$\begin{array}{l}\text { Index } \\
\text { patients }\end{array}$} & \multicolumn{3}{|l|}{ Relatives } & \multirow[t]{2}{*}{ Total } \\
\hline & & First degree* & Second degree $\dagger$ & Third degree $\ddagger$ & \\
\hline Total number in family & 36 & 154 & 372 & 290 & 852 \\
\hline Diaphyseal aclasis confirmed & 36 & 47 & 21 & 12 & 116 \\
\hline Malignant change in exostosis & 0 & 0 & 1 (unconfirmed) & 0 & 1 (unconfirmed) \\
\hline Other malignant disease in patients & 0 & 1 melanoma eye & & & \\
\hline with diaphyseal aclasis & & 1 'Ca spine' (died aged 7 yr) & 0 & 0 & 2 \\
\hline $\begin{array}{l}\text { Malignant disease in relatives } \\
\text { without known diaphyseal aclasis }\end{array}$ & 一 & $\begin{array}{l}2 \text { Ca colon } \\
1 \text { Ca rectum }\end{array}$ & $\begin{array}{l}4 \mathrm{Ca} \text { bronchus } \\
2 \mathrm{Ca} \text { colon } \\
2 \mathrm{Ca} \text { oesphagus } \\
2 \mathrm{Ca} \text { stomach } \\
1 \mathrm{Ca} \text { breast } \\
1 \mathrm{Ca} \text { uterus } \\
1 \mathrm{Ca} \text { kidney } \\
1 \text { 'brain tumour' } \\
1 \mathrm{Ca} \text { liver }\left(? 2^{\circ}\right)\end{array}$ & 0 & 18 \\
\hline Total deaths (excluding perinatal) & 0 & 18 & 114 & 4 & 136 \\
\hline
\end{tabular}

* Parents, sibs, children.

†Grandparents, uncles, aunts, nephews, nieces.

$\ddagger$ First cousins.

TABLE 2 Malignant disease in neurofibromatosis.

\begin{tabular}{|c|c|c|c|c|c|}
\hline & \multirow{2}{*}{$\begin{array}{l}\text { Index } \\
\text { patients }\end{array}$} & \multicolumn{3}{|l|}{ Relatives } & \multirow[t]{2}{*}{ Total } \\
\hline & & First degree* & Second degree & Third degree + & \\
\hline Total number in family & 37 & 170 & 455 & 410 & 1072 \\
\hline Neurofibromatosis confirmed & 37 & 27 & 5 & 1 & 70 \\
\hline $\begin{array}{l}\text { Malignant disease in patients } \\
\text { with neurofibromatosis }\end{array}$ & 0 & $\begin{array}{l}3 \text { fibrosarcoma } \\
1 \text { 'brain tumour' } \\
\text { (unconfirmed) }\end{array}$ & $\begin{array}{l}1 \text { glioblastoma } \\
\text { (neurofibromatosis } \\
\text { unconfirmed) }\end{array}$ & 0 & $\begin{array}{l}3 \text { definite } \\
2 \text { unconfirmed }\end{array}$ \\
\hline $\begin{array}{l}\text { Malignant disease in relatives } \\
\text { without known neurofibromatosis }\end{array}$ & 一 & $1 \mathrm{Ca}$ bronchus & $\begin{array}{l}3 \text { Ca stomach } \\
2 \text { Ca bronchus } \\
1 \text { Paget's disease } \\
\text { (leg amputation, ?malignant) } \\
1 \text { chronic myeloid leukaemia } \\
4 \text { Ca, elderly patients, } \\
\text { type unknown }\end{array}$ & 0 & 12 \\
\hline Total deaths (excluding perinatal) & 0 & 12 & 114 & 5 & 131 \\
\hline
\end{tabular}

* Parents, sibs, children.

† Grandparents, uncles, aunts, nephews, nieces, grandchildren.

$\ddagger$ First cousins.

disease likely to be associated with neurofibromatosis. Thus the proportion with malignant disease was three of $70(4.3 \%)$ or, less certainly, five $(7.1 \%)$. If only those patients over the age of 21 years are considered then the proportion is three or five of $31(9.7$ or $16.1 \%)$. Histories of the five probable cases of malignancy are noted below.

\section{Case 1}

The mother of an index patient with peripheral neurofibromatosis, aged 26 years, developed sciatica. At $28 \frac{1}{2}$ years she developed right leg weakness progressing to paraplegia. Operation showed multiple fibromata of the cauda equina with fibrosarcomatous change. Six months later she developed acute intestinal obstruction with an inoperable tumour pressing upon the rectum and died aged 29 vears 3 months. At necropsy neurofibromatosis of the central and peripheral nervous system was noted, with a hamartoma of the right thalamus and secondary malignant change in neurofibromata involving the leptomeninges, cauda equina, and the right side of the bony pelvis and sacroiliac joint. She had also suffered from pulmonary tuberculosis.

Case 2

The sister of an index patient with peripheral neurofibromatosis, aged 22 years, developed sciatica. Biopsy of a lump in the popliteal fossa showed a neurofibroma. Over the following 2 months the pain worsened and masses developed in the back and abdomen. The former was found to be encapsulated, arising from an intercostal nerve, and was removed. The pathology report only queried malignant change. One month later a neurofibromatous mass in the right iliac fossa was found to be inoperable and 
at 23 years she died from intestinal obstruction and renal failure. There was no necropsy.

\section{Case 3}

The mother of an index patient with peripheral neurofibromatosis, aged 44 years, developed a swelling in the right side of the neck, which gradually became enlarged and painful. Three years later excision/biopsy was carried out, when the mass was found to be deep to the sternomastoid muscle, and the histology was of a highly malignant spindlecelled sarcoma. Special staining methods gave no clear indication of its origin. She died 10 months later aged 48 years. There was no necropsy. She had also suffered from pulmonary tuberculosis.

\section{Case 4}

The maternal uncle of an index patient with peripheral neurofibromatosis died of a highly malignant glioblastoma aged 41 years. There was no evidence that he suffered from overt neurofibromatosis, though it is probably relevant that he had bilateral nerve deafness.

\section{Case 5}

The sister of an index patient with peripheral neurofibromatosis was said to have died of a brain tumour aged 30 years in 1931. No further medical information was available, but it is possible she had neurofibromatosis and malignant disease.

The numbers and site of neoplasms in other first and second degree relatives dying from cancer was unremarkable. If case 4 had neurofibromatosis, then he is the only example in this survey of the 'central' form of the disease.

\section{Discussion}

The number of patients in this survey with malignant change in diaphyseal aclasis $(0.9 \%$ or less) is considerably below previous estimates of 5 to $28 \%$, while the proportion with neurofibromatosis and malignant disease $(4.3$ to $7.1 \%)$ is approximately the same as the lowest of published estimates $(5 \%)$. It is likely, however, that the figures found for both diseases in this survey are still too high and an attempt is made here to calculate upper and lower limits and take the mid-point as a more reasonable estimate.

\section{DIAPHYSEAL ACLASIS}

This is known to be of autosomal dominant inheritance; thus, assuming full penetrance, the theoretical maximum number of affected persons in the population of 852 subjects surveyed here is: 36 index patients with half their 154 first degree relatives affected, one-quarter of their 372 second degree, and one-eighth of their 290 third degree relatives. That is, there is a theoretical maximum of 242 persons with diaphyseal aclasis who are at risk of developing malignant change. Some of the 36 index patients, however, will be new genetic $\vec{\nabla}$ mutations, and thus their relatives (other than their own children) will not be at risk. It is impossible to क know this figure accurately, since the disorder is not $\vec{\circ}$ necessarily apparent clinically, but a 'best guess' for $\overrightarrow{\vec{H}}$ this population, having subtracted the families of $\vec{\omega}$ probable new mutations, is a theoretical minimum of 174 persons with diaphyseal aclasis. While the co inherited disorder is not necessarily clinically i apparent, a malignant bony neoplasm is, and would or certainly be known within the family. Thus, one $\omega$ doubtful case of malignant change in the (theoretical) $\mathrm{c}$ 242 affected persons gives a proportion of $0.4 \%$ or, 은 of 174 persons, $0.6 \%$.

The truth most likely lies between these two figures, malignant change in diaphyseal aclasis probably only $\overrightarrow{0}$ occurring in $0.5 \%$ or less of all cases, or $1.3 \%$ of $\frac{\Phi}{\square}$ those over 21 years of age.

\section{NEUROFIBROMATOSIS}

The same calculation can be made for neurofibromatosis, which is also of autosomal dominant inheritance. The theoretical maximum number of patients with neurofibromatosis in the population of 1072 considered here is 287 . Again, subtracting the families of probable new mutations, a 'best guess' is a $\overrightarrow{\vec{O}}$ theoretical minimum of 145 persons with neurofibromatosis. The malignant disease is more likely to be known in the family than the inherited disorder, and the three confirmed cases in the (theoretical) 287 or 145 affected persons give proportions of 1.0 or $2.1 \%$. Including the two less certain un- $\dot{0}$ confirmed cases gives 1.7 or $3.4 \%$. The truth probably lies between the two extremes, giving a $\delta$ likely figure of approximately $2.0 \%$ for malignant disease developing in association with all cases of 윽 neurofibromatosis, or $4.2 \%$ of those over the age of 21 years.

With so few cases of malignancy available for investigation, it is impossible to be certain, but in or the three patients with definite malignant disease $N$ associated with neurofibromatosis the inherited $N$ disorder was of great severity, and it may be that the risk is greater in such cases and less in persons only mildly involved.

\section{Conclusion}

We believe that the observed proportions with malignant disease in this family survey (diaphyseal aclasis $0.9 \%$ and neurofibromatosis $4.3 \%$ ) are still 
too high an estimate, in view of the likely numbers of subjects only mildly affected by the inherited disease who cannot be identified, whereas those with malignant change will almost certainly be known. Calculating the theoretical maximum and minimum of affected subjects in the population studied and taking the mid-point, a more likely figure for diaphyseal aclasis is $0.5 \%$ and for neurofibromatosis $2.0 \%$ of all cases. Since malignant change is unusual in childhood, a more clinically useful estimate is the proportion of those over 21 years developing malignant disease, which is $1.3 \%$ of those with diaphyseal aclasis and $4 \cdot 2 \%$ of those with neurofibromatosis.

We are grateful to consultants at the Princess Margaret Rose Orthopaedic Hospital, Edinburgh, St Thomas's Hospital, London, Harlow Wood Orthopaedic Hospital, Nottingham, and The Robert Jones and Agnes Hunt Orthopaedic Hospital, Oswestry, for their assistance and permission to review patients. The work was made possible by grants (to RWD) from the St Thomas's Hospital Endowment (Research) Committee and the National Fund for Research into Crippling Diseases, to whom grateful acknowledgement is made.

\section{References}

1 Preston F, Walsh W, Clark T. Cutaneous neurofibromatosis (Von Recklinghausen's disease); clinical manifestation and incidence of sarcoma in sixty one male patients. Arch Surg 1952;64:813-27.

2 Jaffe HL. Tumours and tumorous conditions of the bones and joints. London: Kimpton, 1958.

3 Dahlin DC. Bone tumours. Springfield, Illinois: Thomas, 1957.

4 Heard G. Nerve sheath tumours and Von Recklinghausen's disease of the nervous system. Ann $R$ Coll Surg Engl 1962;31 :229-48.
5 Heard G. Malignant disease in Von Recklinghausen's neurofibromatosis. Proc R Soc Med 1963;502-3.

6 Brasfield FD, Das Gupta TK. Von Recklinghausen's disease: a clinicopathological study. Ann Surg 1972;175: 86-104.

7 Solomon L. Chondrosarcoma in hereditary multiple exostosis. S Afr Med J 1974;671-6.

8 Solomon L. Hereditary multiple exostosis. J Bone Joint Surg $(B r)$ 1963;45:291-304.

9 Madigan R, Worrall T, McClain EJ. Cervical cord compression in hereditary multiple exostosis. $J$ Bone Joint Surg (Am) 1974;56:401-4.

10 Eriksson AI, Schiller A, Mankin HJ. The management of chondrosarcoma of the bone. Clin Orthop 1980;153: 44-66.

11 O'Neal LW, Ackerman LV. Chondrosarcoma of bone. Cancer 1952;5:551.

12 Crowe FW, Schull WJ, Neel JV. A clinical, pathological and genetic study of multiple neurofibromatosis. Springfield, Illinois: Thomas, 1956.

13 Fienman NL, Yakovac WC. Neurofibromatosis in childhood. J Pediatr 1970;76:399.

14 Crawford AH. Neurofibromatosis in pediatric patient. Orthop Clin North Am 1978;9:11-13.

15 Richardson RR, Noronha A, Leetsma J, Siqueira EB. Multiple neoplastic associations with central and peripheral Von Recklinghausen's disease. South Med J 1980;73:1074-7.

16 Kanter R, Eldridge R, Fabricant R, Allen J, Koerber T. Central neurofibromatosis with bilateral acoustic neuroma. Genetics, clinical and biochemical distinction from peripheral neurofibromatosis. Neurology (Minneap) $1980 ; 30: 851-9$.

17 McCarroll HR. Soft tissue neoplasms associated with congenital neurofibromatosis. J Bone Joint Surg (Am) $1956 ; 38: 717-31$.

18 D'Agostino AN, Soule EH, Miller RH. Sarcomas of the peripheral nerves and somatic soft tissues associated with multiple neurofibromatosis (Von Recklinghausen's disease). Cancer 1963;16:1015-27.

19 Hecht F, McCaw B. Neurofibromatosis and malignancy. J Pediatr 1978;94:1010.

Correspondence and requests for reprints to Dr R Wynne-Davies FRCS, 2 Dale Close, St Ebbe's, Oxford OX1 1TU. 